\title{
Spontaneous splenic rupture in a patient with acute promyelocytic leukaemia during induction chemotherapy
}

\author{
Adam Kuba ${ }^{a}$, Tomas Szotkowski ${ }^{a}$, Peter Rohon ${ }^{a}$, Edgar Faber ${ }^{a}$, Peter Turcsanyi ${ }^{a}$, Jaromir Hubacek ${ }^{\mathrm{a}}$, Milena Holzerova ${ }^{\mathrm{a}}$, \\ Vojtech Prasili ${ }^{\mathrm{b}}$, Marie Jarosova ${ }^{\mathrm{a}}$, Karel Indrak ${ }^{\mathrm{a}}$
}

Background. Acute promyelocytic leukaemia (APL) is a subtype of acute myeloid leukaemia with high curability rates. However, it is often accompanied by severe coagulopathy and bleeding risk and thus represents a potentially fatal haematological emergency requiring immediate treatment. Spontaneous splenic rupture is a rare event in all haematological malignancies. Only two clinical cases have been described so far in a setting of APL.

Case report. We report a patient with APL without preceding splenomegaly who underwent urgent splenectomy for spontaneously occurring splenic rupture during induction chemotherapy. After surgery the patient completed induction chemotherapy and achieved complete remission.

Conclusion. This is the second case of spontaneous splenic rupture without preceding splenomegaly in a patient with APL during induction chemotherapy described so far. Our case demonstrates that emergent splenectomy can be lifesaving even in the unfavourable condition of patient with severe immune deficiency.

Key words: acute promyelocytic leukaemia, splenic rupture, splenomegaly, abdominal pain

Received: January 25, 2013; Accepted with revision: November 13, 2013; November 26, 2013

http://dx.doi.org/10.5507/bp.2013.086

${ }^{a}$ Department of Hemato-Oncology, Faculty of Medicine and Dentistry, Palacky University Olomouc and University Hospital Olomouc, Olomouc, Czech Republic

${ }^{b}$ Department of Radiology, Faculty of Medicine and Dentistry, Palacky University Olomouc and University Hospital Olomouc, Olomouc Corresponding author:Tomas Szotkowski, e-mail: tomas.szotkowski@fnol.cz

\section{INTRODUCTION}

APL is a subtype of acute myeloid leukaemia (AML) with specific biological and clinical features and high curability rates due to current treatment possibilities. From a cytogenetic and molecular point of view, it is well characterized by the presence of a balanced reciprocal translocation between chromosomes 15 and 17 (ref. ${ }^{1}$ ) giving rise to a fusion gene $P M L-R A R-a$ whose transcript detection by reverse transcriptase polymerase chain reaction (RT-PCR) has become the golden standard in APL diagnostics and minimal residual disease monitoring ${ }^{2,3}$. Administration of ATRA (all-trans retinoic acid) at a daily dose of $45 \mathrm{mg} / \mathrm{m}^{2}$ in combination with anthracycline-based chemotherapy for induction and consolidation followed by maintenance according to disease risk stratification has become a standard therapy ${ }^{48}$. APL is generally considered a curable disease with excellent long-term prognosis in cases where the initial disease specific and treatment related complications are managed. Cure rates from $80 \%$ to $90 \%$ can be expected in patients who survive induction and achieve complete remission ${ }^{9}$. Because of the high early mortality rate, APL represents a medical emergency. Immediate ATRA administration is essential to decrease the high early mortality rate, mostly resulting from bleeding into the central nervous system, lungs and gastrointestinal tract $^{10}$. Spontaneous splenic rupture (SSR) is a rare but often life threatening complication most often seen in neoplastic disorders ${ }^{11}$. To our knowledge, only two clini- cal cases of SSR during induction chemotherapy of APL have been documented in the literature so far ${ }^{12,13}$. Here we report a case of spontaneously occurring splenic rupture during induction of APL.

\section{CASE REPORT}

A 57-year-old man was referred to our centre from a county hospital where he had been admitted for spontaneously occurring hematomas and febrile periods in combination with newly detected anaemia, thrombocytopenia and the presence of leukemic promyelocytes in the peripheral blood smear. On admission, the patient was in sepsis, complicated by hypotension. No spleen size enlargement was detected at physical examination. The initial blood count and laboratory evaluation showed severe anemia $71 \mathrm{~g} / \mathrm{L}$, thrombocytopenia $30 \times 10^{9} / \mathrm{L}$, mild leukocytosis $13 \times 10^{9} / \mathrm{L}$ and significant CRP and renal function parameter elevation (Table 1). Pronounced coagulopathy was in accordance with general APL manifestation. The patient was assigned to high-risk disease according to Sanz ${ }^{14}$. Abundant intravenous hydration together with antibiotics were started with improvement in renal parameters and significant decrease in CRP. ATRA was administered immediately after suspicion of APL that was confirmed by conventional cytogenetic exam and RT-PCR on the second day after admission. The bone marrow leukemic immune phenotype examination revealed positiv- 

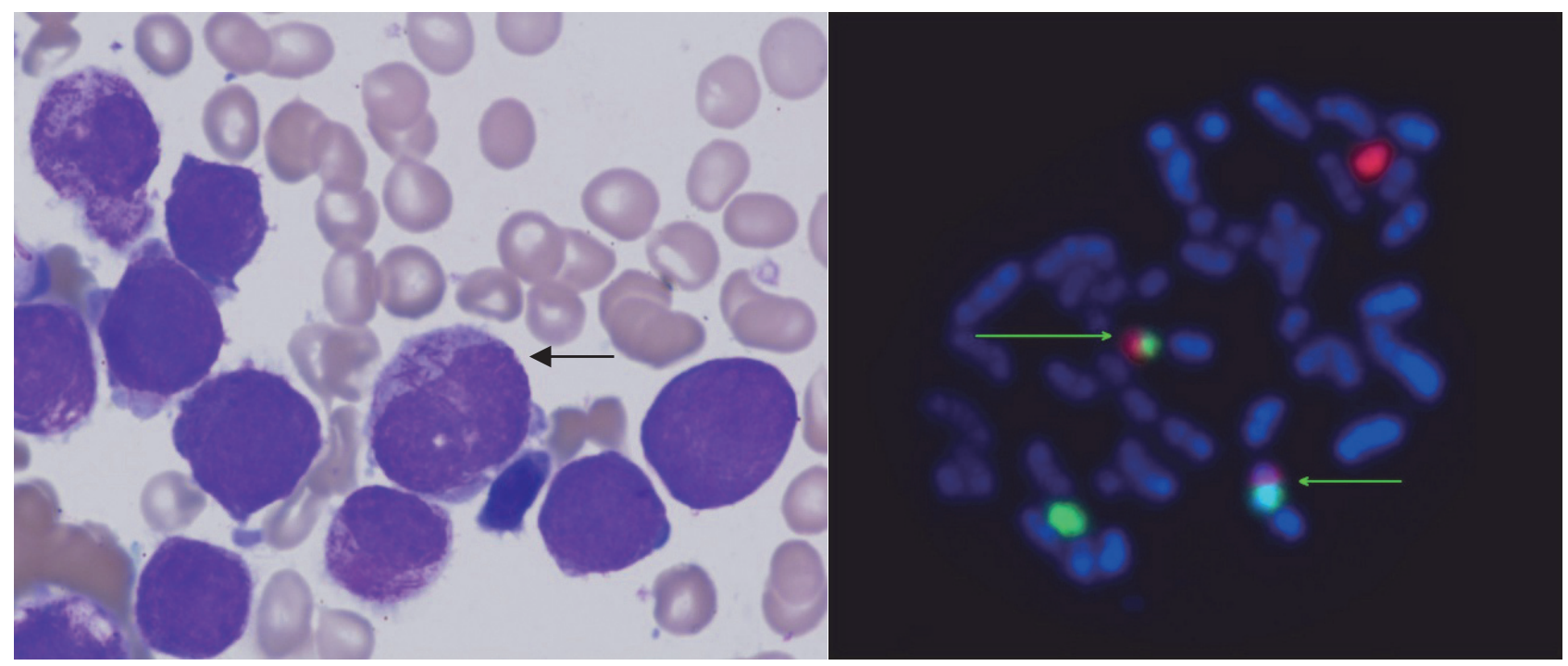

Fig. 1. Bone marrow aspirate showing diagnostic promyelocytes (left) and chromosomal translocation $\mathrm{t}(15 ; 17)(\mathrm{q} 22 ; \mathrm{q} 21)$ diagnostic for APL (right).

Diagnostic bone marrow aspirate showed abundant promyelocytes with typical Auer rods in the cytoplasm (black arrow). Specific reciprocal translocation between chromosomes 15 and 17 was confirmed by the fluorescence in situ hybridisation (green arrows), where green signal corresponds to the promyleocytic leukaemia gene $(P M L)$ on chromosome 15 and the red signal to the retinoic acid receptor-alpha gene $(R A R-\alpha)$ on chromosome 17.

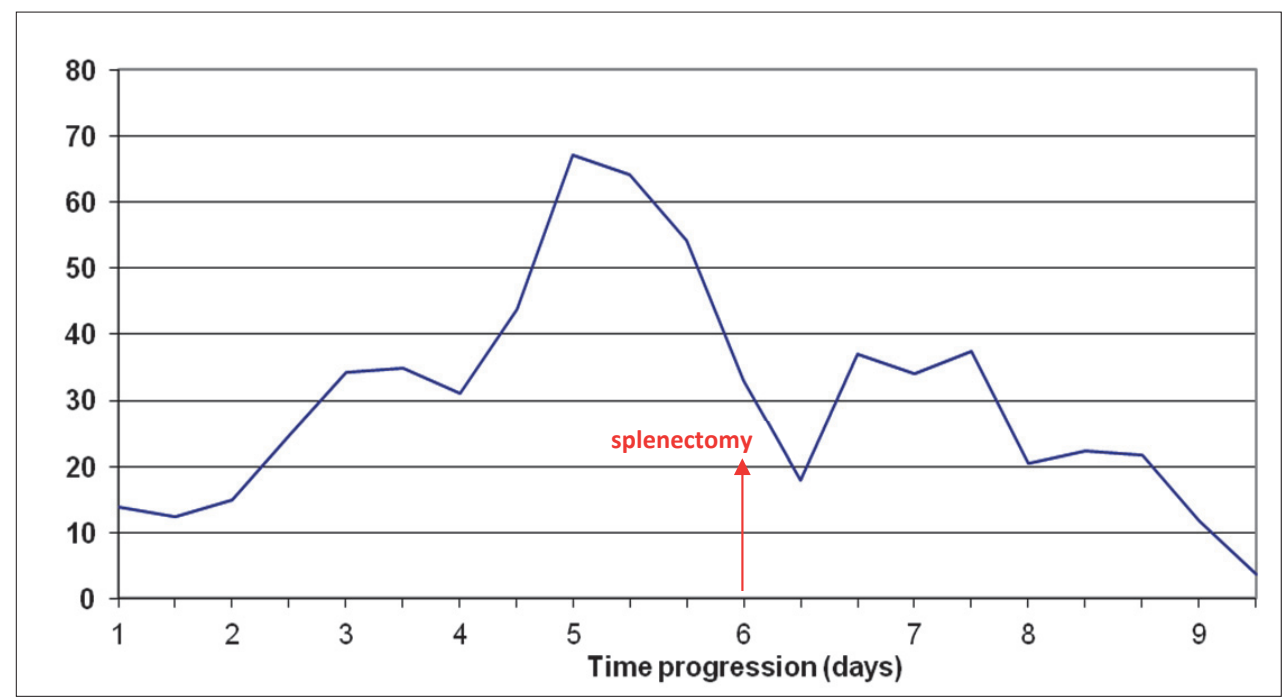

Fig. 2. WBC counts before and after splenectomy.

Graph showing evolution of WBC counts $\left(\times 10^{9} / \mathrm{L}\right)$ with a marked time point (day 6$)$ at which splenectomy was performed.

ity in myeloid markers CD33, CD13, CD65 and CD15. Conventional bone marrow cytogenetic investigation confirmed $\mathrm{t}(15 ; 17)$ and $P M L-R A R$ - $\alpha$ positivity was detected by RT-PCR in both bone marrow and peripheral blood (Fig. 1). Standard induction chemotherapy including ATRA at $45 \mathrm{mg} / \mathrm{m}^{2}$ with idarubicin at $12 \mathrm{mg} / \mathrm{m}^{2}$ was started ${ }^{5}$. During the first 3 days of therapy, the patient developed signs and symptoms of manifested ATRA-syndrome with typical fluid retention and dyspnoea requiring intensive diuretic support and oxygen therapy. Chest X-ray showed signs of mild pulmonary congestion, discrete right-sided fluidothorax and confluent opacities in the basal region of the right lung suggestive of incipient pneumonia. The overall condition corresponded to rapidly increasing leukocytosis reaching almost $70 \times 10^{9} / \mathrm{L}$ on day 3 (Fig. 2). ATRA had to be stopped and hydroxyurea was added instead to the patient's medications as cytoreduction together with corticosteroids. On day 4 of chemotherapy, the patient started complaining about abdominal discomfort with increased flatulence. The abdominal physical exami- 


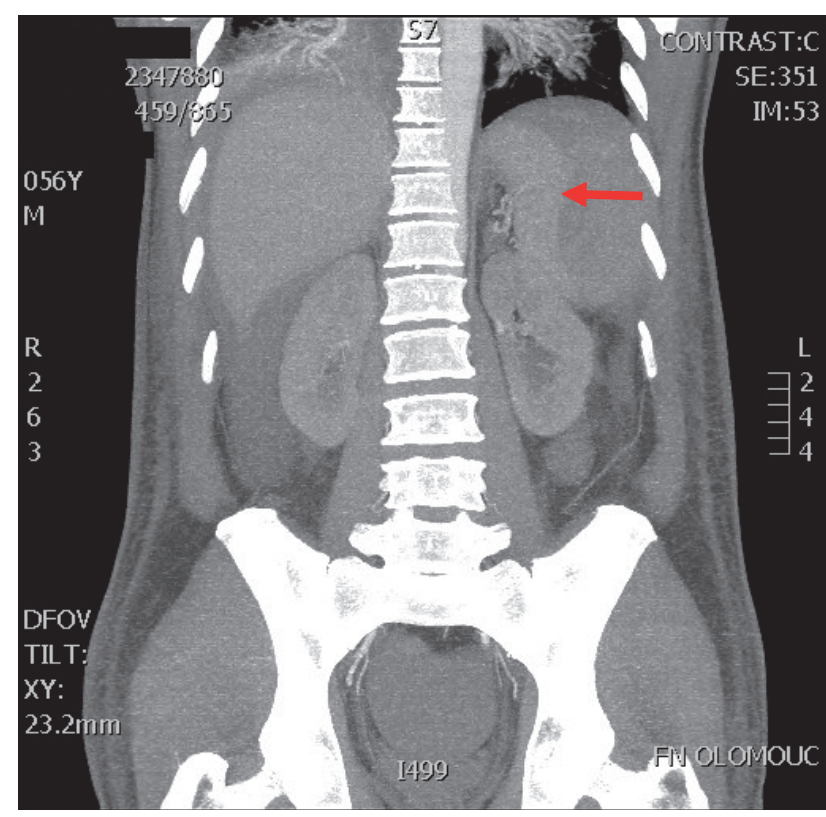

Fig. 3. Abdominal CTA showing SSR with large intraparenchymal haematoma (red arrow).

Large intraparenchymal hematoma of the spleen was detected by CTA with no signs of active bleeding into the peritoneal cavity. nation showed no signs of peritoneal irritation. However, there was extreme drop in haemoglobin level from $76 \mathrm{~g} / \mathrm{L}$ down to $59 \mathrm{~g} / \mathrm{L}$. The patient became severely hypotensive, showing signs of manifested circulatory failure requiring intensive blood and vasopressor support in terms of continual infusion of noradrenaline. Despite intensive packed red cell transfusions there was continuous decrease in haemoglobin level to $42 \mathrm{~g} / \mathrm{L}$ and the patient's overall condition was deteriorating. Computerized tomographic angiography (CTA) of the abdomen showed massive fluid haemorrhagic liquid and SSR with large intraparenchymal hematoma with no signs of active bleeding (Fig. 3). The consultant surgeon indicated splenectomy as a lifesaving emergency intervention. The patient was given 3 transfusion units (TU) of packed red cells, 2 TU of thrombocyte concentrates, 600 units of Prothromplex ( ${ }^{\circledR}$ Baxter) and $4 \mathrm{~g}$ of fibrinogen as preoperative preparation. Blood count and coagulation parameters before substitution are shown in Table 2. Splenectomy was performed without complications. Pathological examination showed a spleen of 120x75x40 mm in size with subcapsular haemorrhagic focus of $65 \mathrm{~mm}$ and parenchymal rupture.

Cytoreduction with hydroxyurea was continued for 3 days and was stopped at the point where white cell count decreased to $3.76 \times 10^{9} / \mathrm{L}$. Resumption the ATRA treatment followed immediately as the oral intake had been restored. The patient completed induction chemotherapy after the transfer to our department on the $4^{\text {th }}$

Table 1. Laboratory values at diagnosis.

\begin{tabular}{|c|c|c|c|c|c|}
\hline \multirow[t]{2}{*}{ Blood count } & $\begin{array}{c}\text { WBC } \\
\left(\times 10^{9} / \mathrm{L}\right)\end{array}$ & \multicolumn{2}{|c|}{$\begin{array}{l}\text { HGB } \\
(\mathrm{g} / \mathrm{L})\end{array}$} & \multicolumn{2}{|c|}{$\begin{array}{c}\text { PLT } \\
\left(\times 10^{9} / \mathrm{L}\right)\end{array}$} \\
\hline & 13.8 & \multicolumn{2}{|c|}{69} & \multicolumn{2}{|c|}{30} \\
\hline Manual differential count & \multicolumn{5}{|c|}{$\begin{array}{l}\text { neutrophil segments } 5 \% \text {, neutrophil bands } 11 \% \text {, neutrophil metamyelocytes } 6 \% \text {, neutrophil myelocytes } \\
10 \% \text {, neutrophil promyelocytes } 56 \% \text {, lymphocytes } 11 \% \text {, blasts } 1 \%\end{array}$} \\
\hline \multirow[t]{2}{*}{ Coagulation } & $\begin{array}{c}\text { Fibrinogen } \\
(\mathrm{g} / \mathrm{L})\end{array}$ & $\begin{array}{l}\text { D-dimers } \\
(\mathrm{ng} / \mathrm{L})\end{array}$ & $\begin{array}{l}\text { APTT } \\
(\mathrm{s})\end{array}$ & $\begin{array}{l}\text { TT } \\
(\mathrm{s})\end{array}$ & $\begin{array}{l}\text { ATIII } \\
(\%)\end{array}$ \\
\hline & 1.70 & 20287 & 28.3 & 12.6 & 90 \\
\hline \multirow[t]{2}{*}{ Biochemistry } & Urea $(\mathrm{mmol} / \mathrm{L})$ & \multicolumn{2}{|c|}{ Creatinine $(\mu \mathrm{mol} / \mathrm{L})$} & \multicolumn{2}{|c|}{$\begin{array}{c}\text { CRP } \\
(\mathrm{mg} / \mathrm{L})\end{array}$} \\
\hline & 13.1 & & & & \\
\hline
\end{tabular}

Patient's pathological blood count, coagulation and biochemical values at admission showing pronounced renal insufficiency and CRP elevation due to sepsis.

Table 2. Blood count and coagulation parameters before preoperative substitution.

\begin{tabular}{|c|c|c|c|c|c|c|}
\hline \multirow[t]{2}{*}{ Blood count } & \multicolumn{2}{|c|}{$\begin{array}{c}\text { WBC } \\
\left(\times 10^{9} / \mathrm{L}\right)\end{array}$} & \multicolumn{2}{|c|}{$\begin{array}{l}\text { HGB } \\
(\mathrm{g} / \mathrm{L})\end{array}$} & \multicolumn{2}{|c|}{$\begin{array}{c}\text { PLT } \\
\left(\times 10^{9} / \mathrm{L}\right)\end{array}$} \\
\hline & \multicolumn{2}{|c|}{33} & \multicolumn{2}{|c|}{42} & \multicolumn{2}{|c|}{39} \\
\hline \multirow[t]{2}{*}{ Coagulation } & $\begin{array}{l}\text { PT } \\
\text { (s) }\end{array}$ & $\begin{array}{c}\text { Fibrinogen } \\
(\mathrm{g} / \mathrm{L})\end{array}$ & $\begin{array}{c}\text { D-dimers } \\
(\mathrm{ng} / \mathrm{L})\end{array}$ & $\begin{array}{c}\text { APTT } \\
(\mathrm{s})\end{array}$ & $\begin{array}{l}\text { TT } \\
(\mathrm{s})\end{array}$ & $\begin{array}{c}\text { ATIII } \\
(\%)\end{array}$ \\
\hline & 15 & 0.9 & 9633 & 23.4 & 15.9 & 110 \\
\hline
\end{tabular}

Coagulopathy, severe anaemia and thrombocytopenia requiring thorough preoperative haematological substitution was revealed. 
postoperative day complicated by febrile neutropenia followed by an episode of hypotension needing vasopressor support. The patient completed the first consolidation chemotherapy with idaurubicin $5 \mathrm{mg} / \mathrm{m}^{2}$ and Ara-C

$1 \mathrm{~g} / \mathrm{m}^{2}$ without any serious complications and is about to start the second consolidation with mitoxantrone 10 $\mathrm{mg} / \mathrm{m}^{2}$ and etoposide $100 \mathrm{mg} / \mathrm{m}^{2}$ according to GIMEMA protocol $^{15}$. The patient has reached $P M L-R A R-\alpha$ negative status in bone marrow currently.

\section{DISCUSSION}

There are very limited data available concerning SSR in APL. Only two clinical cases with SSR in APL were described so far $^{12,13}$. One of them had a moderate splenomegaly at ultrasound examination and the other one had no splenomegaly detected. Therefore, our case report presenting SSR in an APL patient during induction chemotherapy without previous splenomegaly is the second one published so far. SSR is a very rare event. However, according to a systematic review by Renzulli et al., haematological neoplastic disorders represent the largest etiologic group (16.4\%) followed by infectious diseases (14.8\%) (ref. $\left.{ }^{11}\right)$. Non-Hodgkin's lymphomas are reported among the most often to be prone to SSR followed by various types of leukaemia and chronic myeloproliferative disorders. Two cases from our centre with SSR occurring in a patient with diffuse large B-cell lymphoma and a patient with hairy cell leukaemia were published a few years ago $^{16}$. AML represent the third most often aetiological subgroup of SSR of all haematological neoplastic disorders. The highest SSR-related mortality rate is associated with neoplastic disorders and was proven to be significantly related to the presence of splenomegaly and age over 40 years, whereas male sex, primary surgical treatment and multiple aetiological factors were not associated with mortality ${ }^{11}$. Nevertheless, SSR can occur without previous splenomegaly as happened in our APL patient. Tachycardia, hypotension, abdominal pain, nausea, vomiting and rarely occurring Kehr's sign are general symptoms of intra-abdominal haemorrhage. However, their manifestation can be blurred by supportive and concomitant therapy. Abdominal CT and CTA are the diagnostic methods of choice with high sensitivity and specificity as in our case.

\section{CONCLUSION}

Our clinical case demonstrates that emergent splenectomy can be lifesaving even in the severely unfavourable condition in a patient with SSR, severe immune deficiency and manifested coagulopathy after thorough haematological preoperative preparation. It requires an experienced surgical team with excellent multidisciplinary postoperative care.

\section{ABBREVIATIONS}

APL, Acute promyelocytic leukaemia; AML, Acute myeloid leukaemia; RT-PCR, Reverse transcriptase polymerase chain reaction; ATRA, All-trans retinoic acid; SSR, Spontaneous splenic; WBC, White blood cell count; HGB, Haemoglobin (HGB); PLT, Platelets.

\section{ACKNOWLEDGEMENT}

The work was supported by grants VZ MSMT 6198959205 and Faculty of Medicine and Dentistry, Palacky University Olomouc (LF-2013-004).

Author contributions: All authors contributed to data collection, manuscript writing and approved the final version of the manuscript.

Conflict of interest statement: The authors state that there are no conflicts of interest regarding the publication of this article.

\section{REFERENCES}

1. Rowley JD, Golomb HM, Dougherty C. 15/17 translocation, a consistent chromosomal change in acute promyelocytic leukaemia. Lancet 1977;1(8010):549-50.

2. Lo Coco F, Diverio D, Falini B, Biondi A, Nervi C, Pelicci PG. Genetic diagnosis and molecular monitoring in the management of acute promyelocytic leukemia. Blood 1999;94(1):12-22.

3. Grimwade D. The pathogenesis of acute promyelocytic leukaemia: evaluation of the role of molecular diagnosis and monitoring in the management of the disease. Br J Haematol 1999;106(3):591-613.

4. Fenaux $P$, Chastang $C$, Chevret $S$, Sanz M, Dombret $H$, Archimbaud E, Fey M, Rayon C, Huguet F, Sotto JJ, Gardin C, Makhoul PC, Travade P, Solary E, Fegueux N, Bordessoule D, Miguel JS, Link H, Desablens B, Stamatoullas A, Deconinck E, Maloisel F, Castaigne S, Preudhomme C, Degos L. A randomized comparison of all transretinoic acid (ATRA) followed by chemotherapy and ATRA plus chemotherapy and the role of maintenance therapy in newly diagnosed acute promyelocytic leukemia. The European APL Group. Blood 1999;94(4):1192200.

5. Avvisati G, Lo Coco F, Diverio D, Falda M, Ferrara F, Lazzarino M, Russo D, Petti MC, Mandelli F. AIDA (all-trans retinoic acid + idarubicin) in newly diagnosed acute promyelocytic leukemia: a Gruppo Italiano Malattie Ematologiche Maligne dell'Adulto (GIMEMA) pilot study. Blood 1996;88(4):1390-8.

6. Mandelli F, Diverio D, Avvisati G, Luciano A, Barbui T, Bernasconi C, Broccia G, Cerri R, Falda M, Fioritoni G, Leoni F, Liso V, Petti MC, Rodeghiero F, Saglio G, Vegna ML, Visani G, Jehn U, Willemze R, Muus P, Pelicci PG, Biondi A, Lo CF. Molecular remission in PML/RAR alpha-positive acute promyelocytic leukemia by combined alltrans retinoic acid and idarubicin (AIDA) therapy. Gruppo ItalianoMalattie Ematologiche Maligne dell'Adulto and Associazione Italiana di Ematologia ed Oncologia Pediatrica Cooperative Groups. Blood 1997;90(3):1014-21.

7. Tallman MS, Andersen JW, Schiffer CA, Appelbaum FR, Feusner JH, Woods WG, Ogden A, Weinstein H, Shepherd L, Willman C, Bloomfield CD, Rowe JM, Wiernik PH. All-trans retinoic acid in acute promyelocytic leukemia: long-term outcome and prognostic factor analysis from the North American Intergroup protocol. Blood 2002;100(13):4298-302.

8. Sanz MA, Martin G, Rayon C, Esteve J, Gonzalez M, Diaz-Mediavilla J, Bolufer P, Barragan E, Terol MJ, Gonzalez JD, Colomer D, Chillon C, Rivas C, Gomez T, Ribera JM, Bornstein R, Roman J, Calasanz MJ, Arias J, Alvarez C, Ramos F, Deben G. A modified AIDA protocol with anthracycline-based consolidation results in high antileukemic efficacy and reduced toxicity in newly diagnosed PML/RARalpha- 
positive acute promyelocytic leukemia. PETHEMA group. Blood 1999;94(9):3015-21.

9. Tallman MS, Nabhan C, Feusner JH, Rowe JM. Acute promyelocytic leukemia: evolving therapeutic strategies. Blood 2002;99(3):759-67.

10. de la Serna J, Montesinos $P$, Vellenga E, Rayon C, Parody R, Leon A, Esteve J, Bergua JM, Milone G, Deben G, Rivas C, Gonzalez M, Tormo M, Diaz-Mediavilla J, Gonzalez JD, Negri S, Amutio E, Brunet S, Lowenberg B, Sanz MA. Causes and prognostic factors of remission induction failure in patients with acute promyelocytic leukemia treated with all-trans retinoic acid and idarubicin. Blood 2008;111(7):3395-402.

11. Renzulli P, Hostettler A, Schoepfer AM, Gloor B, Candinas D. Systematic review of atraumatic splenic rupture. $\mathrm{Br} J$ Surg 2009;96(10):1114-21.

12. Hernandez R, Del CM, Lopez C, Gonzalez MI, Vazquez ML, Caballero $M D$, San MJ. Pathologic rupture of the spleen during induction with ATRA in a patient with acute promyelocytic leukemia. Med Oncol 2000;17(4):337-9.

13. Lazzarino M, Morra E, Castagnola C, Inverardi D, Dore R, Catona A, Bernasconi $C$. Spontaneous splenic rupture during induction chemotherapy for acute promyelocytic leukemia successfully treated with splenectomy. Haematologica 1990;75(1):84-6.
14. Sanz MA, Lo Coco F, Martin G, Avvisati G, Rayon C, Barbui T, DiazMediavilla J, Fioritoni G, Gonzalez JD, Liso V, Esteve J, Ferrara F, Bolufer P, Bernasconi C, Gonzalez M, Rodeghiero F, Colomer D, Petti MC, Ribera JM, Mandelli F. Definition of relapse risk and role of nonanthracycline drugs for consolidation in patients with acute promyelocytic leukemia: a joint study of the PETHEMA and GIMEMA cooperative groups. Blood 2000;96(4):1247-53.

15. Mandelli F, Diverio D, Avvisati G, Luciano A, Barbui T, Bernasconi C, Broccia G, Cerri R, Falda M, Fioritoni G, Leoni F, Liso V, Petti MC, Rodeghiero F, Saglio G, Vegna ML, Visani G, Jehn U, Willemze R, Muus P, Pelicci PG, Biondi A, Lo Coco F. Molecular remission in PML/ RAR alpha-positive acute promyelocytic leukemia by combined alltrans retinoic acid and idarubicin (AIDA) therapy. Gruppo ItalianoMalattie Ematologiche Maligne dell'Adulto and Associazione Italiana di Ematologia ed Oncologia Pediatrica Cooperative Groups. Blood 1997;90(3):1014-21.

16. Szotkowski T, Szotkowska R, Pikalova Z, Tichy T, Flodr P, Tichy M, Houserkova D, Benysek V, Zlamalova N, Ruzicka V, Indrak K. Spontaneous splenic rupture in two patients with hematologic malignancy. Biomed Pap Med Fac Univ Palacky Olomouc Czech Repub 2007;151(1):113-6. 